\title{
A MODEL OF SIMULTANEOUS EVOLUTION OF COMPETITIVE ABILITY AND HERBIVORE RESISTANCE IN A PERENNIAL PLANT
}

\author{
María Uriarte, ${ }^{1,2,3}$ Charles D. Canham, ${ }^{2}$ and Richard B. Root ${ }^{1}$ \\ ${ }^{1}$ Ecology and Evolutionary Biology, Cornell University, Ithaca, New York 14853 USA \\ 2Institute of Ecosystem Studies, Box AB, Millbrook, New York 12545 USA
}

\begin{abstract}
Plant populations often experience the joint effects of intraspecific competition and herbivory, yet the impact of the interaction of these two factors on the outcome of evolution is largely unknown. Here, we develop a spatially explicit simulation model to examine interactions between the evolution of herbivore resistance and competitive ability in the goldenrod Solidago altissima. We define competitive ability as either competitive effect, the ability of a plant to deplete resources and make them unavailable to competitors, or competitive response, the ability to grow, survive, and reproduce despite depletion of resources by neighboring competitors. We considered symmetric and asymmetric modes of competition and explored the following questions: (1) Does the selective effect of competition differ for the two components of competitive ability? (2) What are the effects of the evolution of competitive ability and resistance on each other? (3) Can trade-offs between competitive ability and resistance emerge, given no relationship between these two traits prior to selection? Our results showed that competitive response evolved quickly regardless of the mode of competition, but self-suppression hindered the evolution of competitive effect. The evolution of resistance appeared to be independent of the evolution of competitive ability. Intraspecific competition was the major selective force in our model. At natural levels of herbivory, selection for resistance played a secondary role in structuring the population. Resistant genotypes were only favored at very low resistance costs. At high cost levels, the costs of maintaining resistance far outweighed the benefits. The selective forces of competition and herbivory resulted in trade-offs between competitive response and herbivore resistance, but only at low costs of resistance. Vigorous growth associated with a high competitive response might translate into trade-offs between herbivore tolerance and resistance. The strong selective effects of competitors, coupled with the weaker selection from herbivores, suggest that plant traits directly associated with growth that confer tolerance to both competitors and consumers may be the targets of selection.
\end{abstract}

Key words: competitive effect; competitive response; goldenrod; herbivore resistance; Solidago altissima; trade-offs.

\section{INTRODUCTION}

Plants have to contend with two major biotic stresses: competition for resources with other plants and loss of tissue to herbivores and pathogens. These two factors often interact in ecological time, complicating the study of the evolution of resistance to enemies independent of the evolution of competitive ability. For instance, feeding by specialist herbivores frequently alters the competitive hierarchy within natural plant communities (Louda et al. 1990, Carson and Root 2000, Weis and Hochberg 2000). As a result, it can be difficult to discern the direct long-term effects of herbivore pressure on plant defense from those resulting from indirect effects of an altered competitive environment.

Another factor that complicates the study of the evolution of competitive ability and resistance is the postulated existence of trade-offs (negative genetic correlations) between the ability of a plant to ward off

Manuscript received 19 July 2001; revised 28 February 2002; accepted 1 March 2002.

${ }^{3}$ E-mail: uriartem@ecostudies.org herbivores and its performance in competition. If resistance is costly, the diversion of resources from growth to defense can hinder competitive ability in the wild (Louda et al. 1990, Herms and Mattson 1992, Niemann et al. 1995, Baldwin and Hamilton 2000; but see Coley et al. 1985).

Although studies of the evolution of resistance to herbivores are numerous (Rausher and Simms 1989, Marquis 1992, Simms 1992, Rausher et al. 1993, Agren and Schemske 1994, Nuñez and Dirzo 1994, Feinblum and Rausher 1995, Mitchell-Olds et al. 1996, Baldwin 1998, Mauricio 1998, Elle et al. 1999, and many others), studies of the evolution of competitive ability in plant populations are relatively scarce despite the recognized importance of competition in structuring plant communities (but see Aarsen 1992, Miller 1995, Annicchiaricco and Piano 1997). This apparent neglect of the subject stems from the difficulty of identifying one plant trait that encompasses all of the manifold definitions of competitive ability. Superior competitors may possess one or more traits such as high photosynthetic rates, early or rapid germination time, plastic 


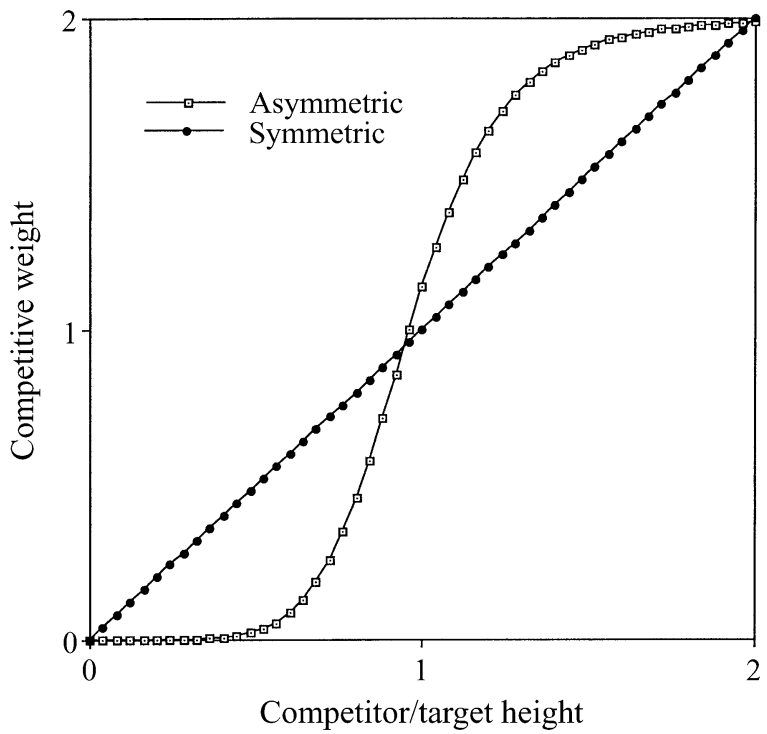

FIG. 1. Functions describing symmetric and asymmetric competition between Solidago altissima (goldenrod) stems.

interpetiolar length, high root: shoot allocation, and deep root system (see review in Grace and Tilman 1990). One approach that bypasses identification of specific traits is to partition competitive ability into two phenomenological components (sensu Goldberg 1990): (1) competitive effect, the ability of a plant to deplete resources and make them unavailable to competitors (e.g., allelopathy, stem elongation in response to shading); and (2) competitive response (or tolerance to competition), the ability to grow, survive, and reproduce despite depletion of resources by neighboring competitors (e.g., growth rate or dark respiration rate).

To explore the evolution of competitive ability, it is also useful to consider the nature of the contested resources (Schwinning and Weiner 1998). For example, competition for light is directional and typically governed by size asymmetries. Competition for soil resources is typically size symmetric and may be determined by abiotic factors, such as nutrient diffusion rates. The mode of competition, i.e., whether individuals compete size symmetrically or asymmetrically, has important implications for the evolution of competitive ability. When plants compete asymmetrically, a larger individual has a disproportionately greater effect on a smaller plant per unit of biomass than does a smaller individual (Fig. 1). In symmetric competition, one plant's effect on another is strictly proportional to size. Asymmetric competition (e.g., for light) should foster the evolution of competitive effect. The reasoning behind this is straightforward; if a plant's fitness depends solely on its ability to intercept light, selection should favor taller individuals, which under asymmetric competition have a disproportionately greater ability to intercept light from shorter, neighboring competitors. If competition is symmetric (e.g., for soil resources) all individuals have an effect on each other proportional to their size, and selection should favor genotypes with high competitive response.

The complex nature of plant competition and its interaction with herbivore damage hinder our understanding of the role that these two factors play in the evolution of natural plant populations. Modeling the interaction between herbivory and competition circumvents some of the problems associated with empirical studies of this topic. In this paper, we use a simulation model to explore the simultaneous evolution of herbivore resistance and the two components of competitive ability, competitive response and competitive effect, in a perennial, clonal plant, the goldenrod Solidago altissima L. We examine how selective pressure from conspecifics on the competitive ability of individual genotypes interacts with selective pressure from herbivores on these same genotypes. Specifically, we address the following questions:

1) How do the two components of competitive ability, competitive response and competitive effect, evolve in a goldenrod population in the absence of herbivores? How does the mode of competition (symmetric vs. asymmetric) affect the evolution of these traits?

2) How does the evolution of competitive ability in a perennial plant population shape the evolution of herbivore resistance? Does the mode of competition (symmetric vs. asymmetric) alter the interaction between the evolution of competitive ability and herbivore resistance?

3) Can trade-offs between herbivore resistance and competitive ability traits emerge as a result of selection from herbivores and competitors, given no correlation between competitive ability and resistance before selection? Are trade-offs more likely under symmetric or asymmetric competition? Do trade-offs vary for competitive effect and competitive response?

\section{Model Formulation}

\section{Basic model structure and initialization}

We have developed a spatially explicit, individualbased simulation model of the demography of Solidago altissima. The model includes population dynamics of both genets and ramets. The model is built with strong linkages to empirical research. We initialize the model by seeding a user-specified number of plants at random locations within a rectangular plot (Table 1). Initial seedling densities were obtained from an 8-yr study of establishment of goldenrod clones in an abandoned agricultural field (Hartnett and Bazzaz 1985a). The plot is treated as a torus (i.e., the edges wrap around to opposite edges) to avoid edge effects. The new seedlings are assigned an initial height drawn from a normal distribution with an empirically derived mean and variance (Table 1). The seedlings are independently assigned an index of herbivore resistance (ranging from 
TABLE 1. Model parameter values and sources.

\begin{tabular}{|c|c|c|}
\hline Parameter & Value & Reference \\
\hline Initial seedling density & $5 / \mathrm{m}^{2}$ & Harnett and Bazzaz (1985a) \\
\hline Initial height, mean (1 SD) & $10(2)$ & Cain $(1990 a)$ \\
\hline RGR decay coefficient & 0.75 & Cain $(1990 a)$ \\
\hline Survival intercept & -4.18 & Cain $(1990 a)$ \\
\hline Survival slope & 0.34 & Cain $(1990 a)$ \\
\hline Rhizome number intercept & 0.037 & Cain $(1990 b)$ \\
\hline Rhizome number slope & 0.039 & Cain $(1990 b)$ \\
\hline Rhizome length $(\mathrm{cm})$, mean (1 SD) & $13.13(7.8)$ & Cain $(1990 b)$ \\
\hline Rhizome angle $\left(^{\circ}\right)$, mean (1 SD) & $-1.49(58.7)$ & Cain $(1990 b)$ \\
\hline $\begin{array}{l}\text { Parental carryover effect range; offset; } \\
\text { decay; exponent }\end{array}$ & $2 ; 4.5 ; 0.0001 ; 2$ & $\begin{array}{l}\text { Goldberg (1987); M. L. Cain } \\
\quad \text { (unpublished data) }\end{array}$ \\
\hline Neighborhood radius $(\mathrm{cm})$ & 25 & Goldberg (1987) \\
\hline Crowding index exponent & 1.5 & Goldberg (1987) \\
\hline Crowding index decay & 0.15 & Goldberg (1987) \\
\hline Herbivore load exponent & 0.05 & Root and Cappuccino (1992) \\
\hline Herbivore load range & 200 & Root and Cappuccino (1992) \\
\hline Maximum ramet height $(\mathrm{cm})$ & 150 & $\begin{array}{l}\text { M. Uriarte and R. B. Root } \\
\text { (personal observation) }\end{array}$ \\
\hline Costs of resistance & $0-0.2$ & user defined $\dagger$ \\
\hline Initial resistance, mean (1 SE) & $0.4(0.2)$ & user defined \\
\hline Symmetric competition slope & 1 & user defined \\
\hline Asymmetric competition asymptote & 2 & user defined \\
\hline Asymmetric competition exponent & -7 & user defined \\
\hline
\end{tabular}

$\dagger$ The user determines which values to assign to this parameter.

0 to 1 ), with the index drawn from a normal distribution. Our model follows Goldberg's (1990) approach and partitions plant resource competition into two components: the competitive effect of a plant on its neighbors, and the competitive response of the plant to a reduction in resource availability due to the presence of neighbors. Each new seedling (genotype) is thus assigned a separate index for competitive effect and response. The exact form and functioning of each index is described in the Competition submodel section.

The model has five basic submodels. Each of the five submodels relies on empirical research to provide the necessary parameter values.

1) The growth submodel uses field data to fit functions that predict plant growth as a result of neighborhood competition, herbivory, and time of the year.

2) The herbivory submodel determines the effect of herbivores on plant growth, drawing from an empirical distribution of insect loads on goldenrod. The degree of herbivory that each plant suffers is a function of resistance.

3) The competition submodel calculates a crowding index based on the characteristics and number of neighbors. The crowding index is a measure of the effect of competitors on plant growth and is derived from previous empirical studies.

4) The mortality submodel determines the likelihood that a plant will die as a function of its position in the competitive hierarchy and the amount of herbivore damage it suffers.

5) The reproduction submodel estimates the recruitment of new ramets into the population at the end of the growing season as a function of plant height. The actual number of ramets is derived from an empirical distribution linking plant height to rhizome production. Rhizome "movement" is also derived from an empirical distribution of rhizome lengths and angles.

\section{Ecological justification}

Tall goldenrod (Solidago altissima, L.) is a native, clonal rhizomatous perennial (Cronquist 1980, Werner et al. 1980) with a highly diverse insect fauna of $>100$ species (Root and Cappuccino 1992, Root 1996). Tall goldenrod has received extraordinary attention from the ecological community. Its conspicuousness, easy germination, and hardiness make it ideal for the study of population dynamics of perennial plants. There are abundant fitness data of various life stages as well as information on the effects of the two factors of interest in our simulation, intraspecific competition and herbivory, on plant fitness (Goldberg 1987, 1988, Cain 1990a, Cain et al. 1991, Root 1996). Moreover, heritable variation in resistance to herbivores has been demonstrated for many insect herbivores (Maddox and Root 1987, McCrea and Abrahamson 1987, Abrahamson et al. 1988, Anderson et al. 1989). There are also abundant data on its clonal "movement" and population dynamics (Cain 1990b, Cain et al. 1991). Finally, we have a good understanding of the frequency and intensity of herbivore loads in a large spatial sample of goldenrod populations (Root and Cappuccino 1992).

This wealth of empirical research gives us a unique opportunity to understand the role that herbivores and intraspecific plant competition play in the evolution of a perennial plant population.

\section{Plant growth submodel}

In western New York State, USA, aboveground growth of $S$. altissima begins in late April and early 
May. The plants senesce in October, after producing rhizomes. The model accommodates the phenology of this growing season by dividing each year into five months (time steps) from May through September. Empirical studies have shown that the maximum potential relative growth rate $\left(\mathrm{RGR}_{\mathrm{pot}}\right)$ in natural populations declines exponentially throughout the growing season (Cain 1990a) according to the equation:

$$
\mathrm{RGR}_{\text {pot }}=\exp (-0.75 \text { month })
$$

where month $=1,2, \ldots, 5$ for May through September. The actual RGR ( RGR $\left._{\text {act }}\right)$ of a plant in any given month is a fraction $A$ of $\mathrm{RGR}_{\text {pot }}$, with $A$ varying as a function of (1) the effects of herbivory $(H)$ in that month, which, in turn, are a function of both herbivore load and herbivore resistance; (2) a parental carryover effect $(P)$, in which there is an effect of final plant height in the previous year on the growth rate of daughter ramets the next year; (3) a crowding index (CI) that incorporates the competitive effects (CE) of neighbors; (4) the competitive response (CR) of the target plant to the competitive effects of neighbors; and (5) a direct cost (Cost) of resistance in terms of potential growth:

$$
A=H \times P \times \mathrm{CI} \times \mathrm{CR} \times \text { Cost. }
$$

Model calculations for the components of this equation are described in subsequent sections of the Methods.

At the end of each month, the model calculates the new height of the ramet as a function of ramet height at the beginning of the month and $\mathrm{RGR}_{\mathrm{act}}$ :

$$
\text { Height }_{t+1}=\exp \left(\left(0.3 \mathrm{RGR}_{\text {act }}+\ln \left(\text { height }_{t}\right)\right) .\right.
$$

\section{Herbivory submodel}

The relative effect of herbivores $(H)$ on RGR is a function of both the herbivore load (load) and plant resistance $(R)$. The value of $R$ is a relative measure of the fitness of a particular genotype in the population when attacked by herbivores. $H$ is scaled to range from 0 for plants with 0 resistance in months with maximum herbivore load ( $\left.\operatorname{load}_{\max }\right)$ to 1 for plants with a resistance of 1 , or in months with no herbivore load (load); see Table 1. Thus,

$$
H=\left(\operatorname{load}_{\max }-(\operatorname{load}(1-R)) / \operatorname{load}_{\max } .\right.
$$

The absolute magnitude of the effect of resistance on height growth will be proportional to herbivore load. Highly resistant genotypes will have faster growth than less resistant genotypes in months with high herbivore load, but the difference will decline as herbivore load declines. The maximum herbivore load and range (in milligrams of insects per meter of stem length) was taken from an extensive survey of 22 goldenrod fields over a 6-yr period (Root and Cappuccino 1992).

Annual herbivore load was drawn randomly from a negative exponential distribution of herbivore load, based on long-term records of temporal variation in insect abundance in 22 goldenrod fields in western New York (Root and Cappuccino 1992). Total load was measured in milligrams of herbivore mass per meter of goldenrod stem.

Because goldenrod colonizes disturbed areas, often at some distance from existing populations, herbivore loads in the initial years of the population may be lower (R. B. Root, personal observation). It is possible that resistance costs may dominate clonal expansion at this early stage when herbivory is infrequent and competition unimportant. Thus, herbivore loads were not applied until the fifth year of the simulations. Goldenrod populations are usually well established five years after the initial colonization event (Hartnett and Bazzaz 1985a). Similarly, herbivore loads may be lower at the later stages of succession. Invasion by woody plants changes microclimatic conditions and probably reduces habitat quality for insect herbivores. Additionally, an overall increase in population resistance may decrease the probability that insects will colonize and reproduce in late-successional fields. To account for these potential changes in habitat suitability for herbivores, we reduced herbivore loads by $40 \%$ after 30 yr of succession. Empirical evidence has demonstrated a reduction in herbivore abundance of this magnitude in late-successional fields (Uriarte 2000).

It may seem a bit unrealistic to lump the effects of a large and varied community of herbivores into a composite herbivore load. However, previous studies of the effects of various herbivores on goldenrod communities have shown that only a few of these insects have measurable effects on plant fitness (Root and Cappucino 1992). Furthermore, goldenrod seems to develop resistance to "suites" or groups of insects, making the use of a composite metric of herbivory more compelling (Maddox and Root 1990).

\section{Direct cost of resistance}

The herbivore resistance term $(R)$ has a positive effect on growth that is proportional to the herbivore load. In years with little or no herbivore load, the term by itself has little or no effect on ramet growth. It is plausible that there is a direct cost of resistance, in terms of potential growth, regardless of herbivore load. The magnitude of the cost could vary for many reasons, including the nature of the defense and the metabolic costs of implementing the defense. The Cost term in Eq. 2 is calculated as:

$$
\text { Cost }=1-(\operatorname{Rrc}) \text {. }
$$

We assumed that the metabolic costs of resistance (rc) increases linearly with resistance levels. As rc increases, ramet growth rate $\left(\mathrm{RGR}_{\mathrm{pot}} A\right)$ will decrease as herbivore resistance increases. We did not assume that rc varies among genotypes, but instead used a single value for all ramets. We have no direct data on the magnitude of the direct cost of resistance, but instead 
TABLE 2. Effects of mode of competition (symmetric vs. asymmetric) on height, density, and number of neighbors per square meter, number of genotypes after selection, and height variation within a genotype; and effects on the evolution of competitive effect, competitive response, and resistance in the absence of herbivore pressure.

\begin{tabular}{|c|c|c|c|c|c|}
\hline \multirow[b]{2}{*}{ Parameter } & \multicolumn{2}{|c|}{ Symmetric } & \multicolumn{2}{|c|}{ Asymmetric } & \multirow[b]{2}{*}{$P$} \\
\hline & Mean & $1 \mathrm{SE}$ & Mean & $1 \mathrm{SE}$ & \\
\hline Height & 69.59 & 1.45 & 78.48 & 1.7 & $<0.0001$ \\
\hline Density (no./m²) & 97.89 & 1.61 & 107.65 & 1.4 & $<0.0001$ \\
\hline Number of neighbors $/ \mathrm{m}^{2}$ & 8.01 & 0.38 & 8.90 & 0.03 & $<0.0001$ \\
\hline Number of genotypes & 103.30 & 8.53 & 113.20 & 9.48 & 0.01 \\
\hline Variation in height within a genotype & 12.01 & 0.24 & 13.12 & 0.38 & $<0.0001$ \\
\hline Competitive effect & 1.038 & 0.01 & 1.038 & 0.01 & 0.97 \\
\hline Competitive response & 1.14 & 0.002 & 1.13 & 0.002 & 0.007 \\
\hline Resistance & 0.33 & 0.02 & 0.309 & 0.028 & 0.04 \\
\hline
\end{tabular}

Notes: Data are from the end of $40-\mathrm{yr}$ runs $(n=10$ runs $)$; df $=1,18$. The cost of resistance is rc $=0.10$.

used the model to conduct sensitivity tests of the effects of rc values ranging from $0-0.2$ (Table 1).

\section{Competition submodel}

Intraspecific competition is generally much stronger than interspecific competition in S. altissima, given its strong dominance in old fields (Goldberg 1987). In our model, competition intensity is assumed to be proportional to the number and height of conspecific neighbors within a $25 \mathrm{~cm}$ radius, based on Goldberg's (1988) study of the effective size of competitive neighborhoods. The model calculates a crowding index (CI) based on the effective density of ramets within the 25 $\mathrm{cm}$ radius neighborhood:

$$
\mathrm{CI}=\exp \left(-\alpha\left(\sum_{j} \text { effective density }_{j}\right)^{\beta}\right) .
$$

The parameters $\alpha$ and $\beta$ were set at 0.15 and 1.5 , respectively, based on Goldberg (1987: Fig. 2) (Table 2). Rather than simply summing the total number of ramets within the neighborhood, effective density weighs each ramet as a function of (1) its height relative to the target plant, (2) the effect of relative size on competitive intensity (which varies depending on whether competition is symmetric or asymmetric), and (3) the genetically determined competitive effect (CE). Under symmetric competition, the effect of one plant on another is strictly proportional to its size relative to the target (Fig. 1). Thus, the contribution of neighbor $j$ to effective density under symmetric competition is:

$$
\text { effective density }_{j}=\frac{\text { height }_{\text {neighborj }}}{\text { height }_{\text {target }}} \gamma \mathrm{CE}_{j}
$$

where $\gamma$ is a constant (Table 1). Under asymmetric competition, a taller neighbor has a disproportionately greater effect on shorter target plants, per unit height (Fig. 1). Thus, under asymmetric competition:

$$
\text { effective density }{ }_{j}=\mathrm{CE}_{j} \frac{\lambda}{1+\left(\frac{\text { height }_{\text {neighbor } j}}{\text { height }_{\text {target }}}\right)^{\delta}}
$$

where $\lambda$ determines the asymptote and $\delta$ determines the steepness of the slope of the sigmoidal function in Fig. 1. Values for all of these parameters are given in Table 1.

Competitive effects.-As mentioned previously, the model allows separate consideration of the competitive effects of plants on neighbors and the competitive responses of target plants to neighbors (sensu Goldberg 1990). Competitive effect in our model can represent a variety of plant traits including plant architecture and belowground allocation of resources (Louda et al. 1990). The competitive effect of ramet $j\left(\mathrm{CE}_{j}\right)$ is genetically determined and is passed on directly to daughter ramets. Thus, when the model is initialized, genotypes are randomly assigned a competitive effect drawn from a normal distribution centered around 1, with a user-determined mean and variance.

Competitive responses.-The model allows variation between ramets in their competitive response to the effective density of neighbors through the term CR. Competitive response in our model represents the ability to grow in the presence of neighbors, and is factored directly into RGR. As with competitive effects, competitive response is assumed to be a function of genotype and is passed on directly to daughter ramets. Thus, CR is assigned to genotypes during initialization of the model. CR has the same distribution as CE.

\section{Mortality submodel}

Mortality of ramets of S. altissima occurs predominantly toward the end of May (Cain 1990a). Small ramets have a much higher probability of death than large ramets. Over $90 \%$ of ramets that die early in the season are $<10 \mathrm{~cm}$ in height (Cain 1990a). Thus, the probability of survival $(p)$ of ramets from one month to the next during a growing season was modeled as a logistic function of ramet height (height) at the beginning of the month:

$$
\log \left(\frac{p}{1-p}\right)=a+b \text { height }
$$

where $a$ and $b$ are parameters estimated using data from Cain (1990a) (Table 1). In effect, we assume that any effects of herbivory and competition on ramet survival 
are mediated through effects on ramet growth and height.

\section{Rhizome production submodel}

Recruitment of new ramets from seed is very rare after the initial establishment of a population of $S$. altissima (Hartnett and Bazzaz 1985a). In the model, all ramets in subsequent years are assumed to arise through vegetative reproduction via rhizomes. Field studies show that the expected number of rhizomes produced at the end of each year is an approximately linear function of the height of the parent ramet (Hartnett 1990):

$$
n=a+b \text { (height). }
$$

The actual number of rhizomes produced by an individual ramet was modeled stochastically as a Poisson function of the expected number of rhizomes, $n$ (Table $1)$.

Rhizome lengths are approximately normally distributed, with a mean and $1 \mathrm{SD}$ of $13.14 \pm 7.81 \mathrm{~cm}$ (Cain 1990b). Rhizomes generally extend along the axis established in the previous year, with variation to either side that is again normally distributed, with a mean of $-1.49^{\circ}$ and a standard deviation of $58.77^{\circ}$, regardless of the number of rhizomes produced (Cain $1990 b$ : Table 1). New ramets in the next spring retain the herbivore resistance $(R)$, competitive effect $(\mathrm{CE})$, and competitive response (CR) of the parent ramet. Initial heights of the ramets at the beginning of the next spring are drawn from a random distribution (Table 1).

\section{Parental size carryover effect}

It has been argued that herbivory is unlikely to affect fitness in perennial plants because the plants can reverse the effects of herbivore damage by drawing on stored resources and allocating resources for asexual reproduction in the following year. However, a large plant is likely to produce a large daughter plant because it can accumulate more resources in belowground structures that can be used to give the daughter an initial jump-start on growth in the following season. In goldenrod, the size (height) of the parent plant has a strong effect on the size and fitness of the daughter plant because larger parents can allocate more vegetative biomass to belowground resources and rhizome production (Schmid et al. 1995). The parental carryover term $(P)$ in the model alters the RG of ramets as a positive, sigmoidal function of the height of the parent ramet:

$$
P=\text { offset }+\operatorname{range}\left(1-\exp \left(-\alpha \text { height }_{\mathrm{p}}^{\beta}\right)\right)
$$

where offset and range are the minimum and range of the parental carryover function, respectively; height $t_{p}$ is the height of the parent ramet; and $\alpha$ and $\beta$ are parameters that control the shape of the sigmoidal increase in $P$ with parent ramet height (Table 1). Parameter values for the terms in Eq. 11 were drawn from M. L. Cain (unpublished data) and Goldberg's (1987) data.

\section{Model output and analysis}

At the end of each time step (i.e., one month within a growing season), we recorded the density, mean height, resistance, competitive effect, and competitive response of live ramets. We also recorded height, resistance, competitive effect, and competitive response of all individual ramets alive at the end of each run (40 yr). We ran the model for $40 \mathrm{yr}$ because this seems to be a reasonable estimate for the potential life-span of a goldenrod field. Because each genotype in the initial population at time 0 was assigned a unique value of resistance, we could determine the number of genotypes remaining at the end of the simulation. We ran 10 replicate simulations for each unique combination of parameter values, and report the mean behavior of the 10 replicates.

Our model depicts the evolution of an asexual population under the selective forces of competition and herbivory. Clonal expansion, i.e., the amount and size of ramets produced by each genotype over the course of simulations, can be used as a surrogate of fitness. The rate of clonal expansion for each of the genotypes over the course of the simulation was calculated as the sum of the end-of-season heights of all ramets for each genotype, summed over all years. Seed production is proportional to final ramet height, so lifetime seed production would be proportional to this sum (Schmid et al. 1995). Thus, we can consider that our model depicts one generation of selection. This assumption allowed us to conduct a selection gradient analysis (Lande and Arnold 1983) to understand the selective effects of resistance and the two components of competitive ability on our goldenrod population. Selection gradient analysis measures links between fitness and particular traits independent of other measured correlated traits. Selection coefficients are obtained as standardized partial regression coefficients from a multiple linear regression of fitness on the traits of interest. We expressed regression coefficients in units of standard deviation to allow comparisons between regression coefficients of the three traits of interest: resistance, competitive effect, and competitive response.

We also conducted nonlinear, quadratic multiple regression analyses that included resistance, competitive effect, and competitive response as predictor variables of a genotype's fitness. These analyses estimate both partial changes in the variance of the trait of interest (stabilizing or disruptive selection) and partial changes in the covariance between two characters, accounting for selection that specifically targets combinations of two traits, e.g., resistance and competitive ability (Brodie et al. 1995). Data were standardized $(z=0, \mathrm{SD}=$ 1) prior to analyses. We analyzed all data using SAS (SAS Institute 1997).

\section{Model Assumptions}

We make the following assumptions:

1) Plants do not "forage," i.e., they do not have the 
ability to alter the length or direction of rhizomes in response to environmental cues. The number, length, and direction of rhizomes are derived from empirical data that take into account plant size. In addition, plants do not make allocation decisions; rhizome production is solely a function of plant size.

2) Resistance and competitive ability do not depend on the environmental context; they are fixed for each genotype. Resources are fixed and remain constant in our simulations.

3) Plants do not reproduce sexually. Any evolution of resistance or competitive ability results from differential ramet survivorship and clonal reproduction rather than differential seed production and survivorship. In natural goldenrod populations, recruitment from seed occurs primarily during the first few years after establishment, so this assumption seems reasonable for the study of long-term population dynamics (Hartnett and Bazzaz 1985a, Morris et al. 1986).

4) Insect damage is spatially uniform across the population. Resistance is the only factor that determines the amount of herbivore damage a plant receives.

5) There are no physical connections between members of the same genet. Sister ramets belonging to the same genet do not share resources. However, our parental carryover effect is a mode of resource sharing between mother and daughter ramets. There are two justifications for this approach. First, resource sharing does occur between mother rhizome and daughter ramets, but not between sister ramets. Instead, sister ramets compete for resources from the common mother rhizome (Abrahamson et al. 1991). Second, severing rhizome connections increases ramet growth in Solidago altissima and decreases competition between sister ramets so that, if anything, we are underestimating the effect of competition on goldenrod populations (Schmid and Bazzaz 1987, Abrahamson et al. 1991). Thus, this assumption is conservative.

6) The population is monospecific. We do not allow other plant species to invade the initial goldenrod population and, as a result, we disregard interspecific competition. Although interspecific competition may become important at late-successional stages, competition between goldenrods is primarily intraspecific (Goldberg 1987).

\section{RESULTS}

\section{Selection on competitive ability in the absence of herbivore damage}

We carried out extensive simulations to explore the effects of selection from intraspecific competition on the evolution of competitive effect and competitive response in the absence of herbivores. We allowed simultaneous evolution of the two components of competitive ability and examined the consequences of such evolution for the population dynamics of Solidago altissima. Finally, we compared the evolution of com-

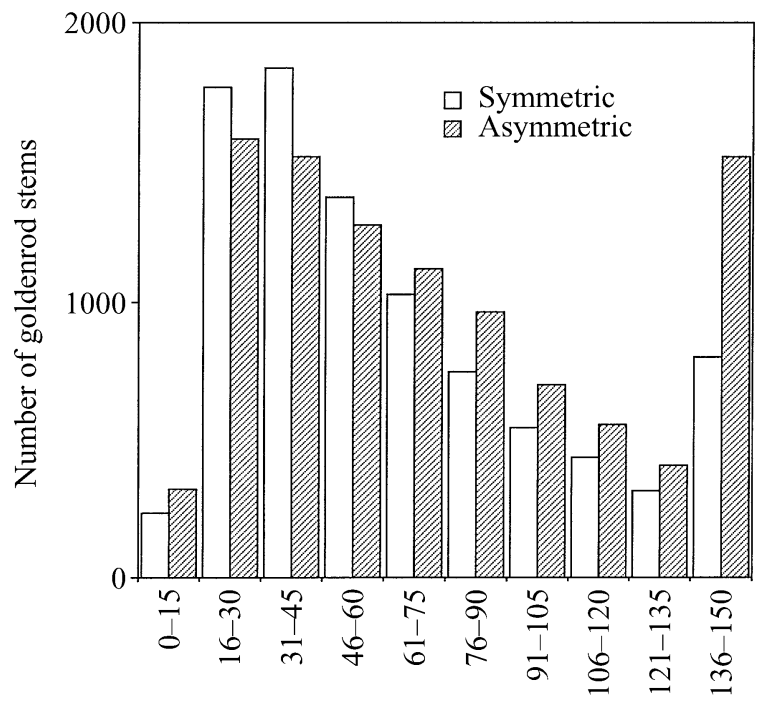

Height of goldenrod (cm)

FIG. 2. Height distribution of plants in a Solidago altissima population after $40 \mathrm{yr}$ of selection under symmetric and asymmetric competition.

petitive ability under symmetric and asymmetric competition.

We started with an initial population of 500 genotypes (seedlings) that varied in their competitive response and competitive effect. The genotypes were spread at random over a $100 \mathrm{~m}^{2}$ area to produce seedling densities in the range encountered in recently abandoned agricultural fields (Hartnett and Bazzaz 1985a). We followed the evolution of these traits in the population after $40 \mathrm{yr}$ of intraspecific competition pressure. Herbivores were absent in these initial simulations.

Stem density was slightly greater under asymmetric than under symmetric competition (Table 2). There was considerable variation in ramet height in the population (Fig. 2). Goldenrods experiencing asymmetric competition were, on average, $9 \mathrm{~cm}$ taller and had a few more genotypes after $40 \mathrm{yr}$ of selection than did populations experiencing symmetric competition (Table 2). As expected, size inequalities were slightly greater under asymmetric competition, with more individuals in the largest size category and fewer in the smaller size categories (Table 2, Fig. 2).

Competition reduced the number of genotypes from an initial 500 to an average of 108 in $40 \mathrm{yr}$ (Table 2). The selective effects of competition on the two components of competitive ability were strikingly different. Competitive response (CR), the ability of a plant to grow and reproduce under competition, always increased in the population (Fig. 3). In contrast, competitive effect (CE), the ability of a genotype to suppress its neighbors, remained stable after $40 \mathrm{yr}$ of competition (Fig. 3). Two opposing forces prevented the evolution of CE. Genotypes with high CE were not favored by selection becaused they suppressed sister 


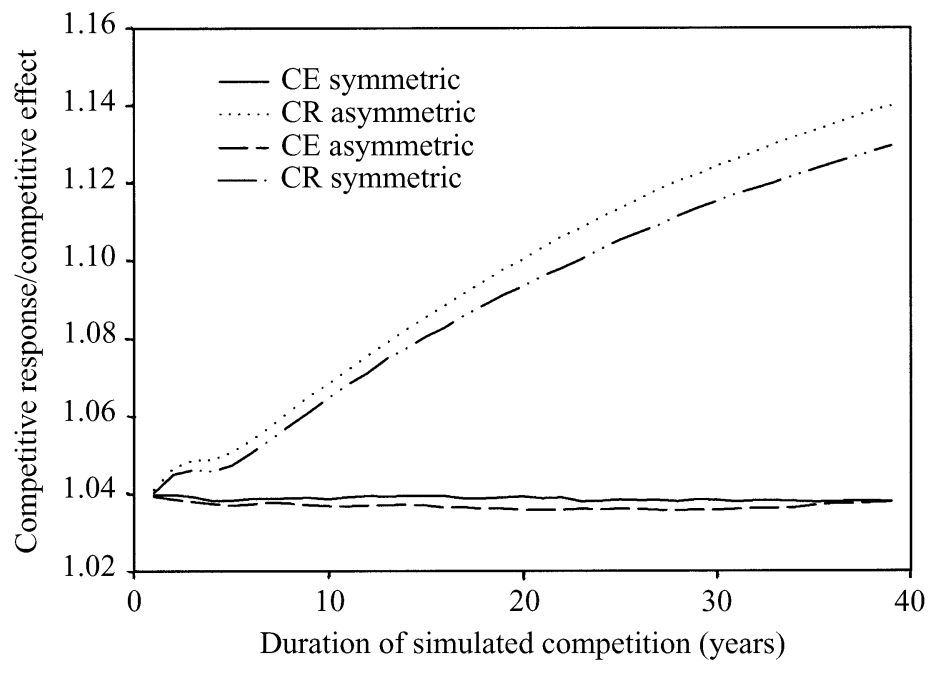

FIG. 3. Evolution of competitive effect (CE) and competitive response (CR) over $40 \mathrm{yr}$ of selection under symmetric and asymmetric competition. Data represent means for $1040-y r$ runs.

ramets from the same genotype, which were likely to be in the neighborhood immediately following rhizome production. Simultaneously, selection acted against genotypes with low $\mathrm{CE}$ that were unable to suppress nonkin neighbors. The mode of competition did not alter the evolutionary trajectory of CE (Table 2, Fig. 3). However, CR increased to higher levels under symmetric than asymmetric competition (Table 2, Fig. 3). The effects of neighbors of taller neighbors on a genotype with low CR were less marked under symmetric than asymmetric competition.

\section{Interactions between evolution of resistance and evolution of competitive ability}

In these simulations, we drew annual herbivore loads from a negative exponential distribution of insect abundance, based on a sampling of 22 fields over six years in western New York (Root and Cappucino 1992). The rate of genet mortality was steady for the first $30 \mathrm{yr}$, decreasing only in the later stages of succession when we applied a reduced herbivore load. After the initial $30 \mathrm{yr}$, lower herbivore loads reduced the benefits of resistance and intensified the fitness consequences of high resistance costs (Fig. 4).

We failed to detect an interaction between the evolution of competitive ability and the evolution of resistance (Tables 2 and 3). Competitive ability evolved to similar levels, regardless of herbivore pressure. Although mode of competition did not affect the evolution of resistance, costs of resistance were crucial determinants of a genotype's performance (Table 3). As expected, increasing resistance costs hindered the evolution of resistance in all cases (Table 4, Fig. 4). In line with our previous findings, resistance costs had no effect on the evolution of competitive ability (Table 4).

Directional selection gradient analyses, measuring the effect of selection on each trait independent of selection on correlated traits $(\beta)$, revealed strong selec- tion on competitive response (Table 5). Fitness benefits of herbivore resistance were only present at very low resistance costs (Table 5). Goldenrod fitness was unaffected by competitive effect, regardless of herbivore resistance costs (Table 5). At high costs, herbivore resistance had a negative effect on fitness (Table 5). As a result, mean competitive response of the population was similar at all levels of resistance costs.

\section{Emergent trade-offs between herbivore resistance and competitive ability}

We detected no trade-offs between competitive effect and resistance after $40 \mathrm{yr}$ of selection (Table 3). Tradeoffs between competitive response and resistance emerged in our simulations, despite the fact that no initial correlation between competitive response and resistance existed before the population underwent selection (Table 4). The strength of these trade-offs was similar under symmetric and asymmetric competition.

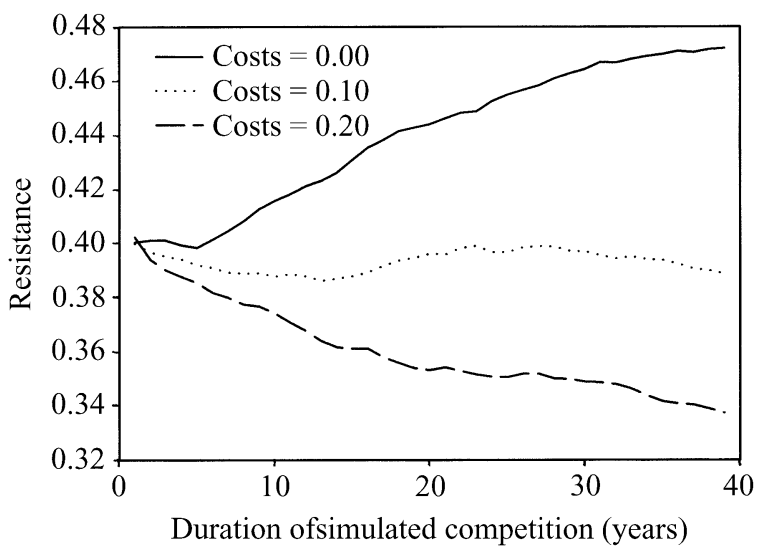

FIG. 4. Variation in the evolution of herbivore resistance at various levels of resistance costs. Data represent means for 10 40-yr runs. 
TABLE 3. Effects of mode of competition (symmetric vs. asymmetric) on final number of genotypes, competitive effect, competitive response, and resistance after 40 years of selection pressure from herbivores.

\begin{tabular}{|c|c|c|c|c|c|}
\hline \multirow[b]{2}{*}{ Parameter } & \multicolumn{2}{|c|}{ Symmetric } & \multicolumn{2}{|c|}{ Asymmetric } & \multirow[b]{2}{*}{$P$} \\
\hline & Mean & $1 \mathrm{SE}$ & Mean & $1 \mathrm{SE}$ & \\
\hline $\begin{array}{l}\text { Number of genotypes } \\
\text { Competitive effect } \\
\text { Competitive response } \\
\text { Resistance }\end{array}$ & $\begin{array}{r}100.1 \\
1.03 \\
1.13 \\
0.39\end{array}$ & $\begin{array}{l}1.16 \\
0.003 \\
0.001 \\
0.001\end{array}$ & $\begin{array}{r}106.6 \\
1.03 \\
1.13 \\
0.40\end{array}$ & $\begin{array}{l}1.16 \\
0.003 \\
0.001 \\
0.01\end{array}$ & $\begin{array}{l}0.07 \\
0.60 \\
0.54 \\
0.70\end{array}$ \\
\hline \multicolumn{6}{|l|}{ Trade-offs } \\
\hline $\begin{array}{l}\text { Resistance vs. competitive effect } \\
\text { Resistance vs. competitive response } \\
\text { Competitive effect vs. competitive response }\end{array}$ & $\begin{array}{l}-0.0026 \\
0.04 \\
-0.015\end{array}$ & $\begin{array}{l}0.03 \\
0.04 \\
0.04\end{array}$ & $\begin{array}{r}-0.01 \\
0.06 \\
0.02\end{array}$ & $\begin{array}{l}0.03 \\
0.04 \\
0.04\end{array}$ & $\begin{array}{l}0.43 \\
0.77 \\
0.54\end{array}$ \\
\hline
\end{tabular}

Notes: Data are from the end of $40-\mathrm{yr}$ runs $(n=10)$; $\mathrm{df}=1,58$. Results are averaged for resistance costs, $\mathrm{rc}=0.0,0.10$, and 0.20 .

Resistance costs were the major determinant of the direction and strength of the trade-offs (Table 4). At high resistance costs $(\mathrm{rc}=0.20)$, there was a positive relationship between resistance and competitive ability (Table 4, Fig. 5). Intermediate resistance costs ( $\mathrm{rc}=$ $0.10)$ produced a flat relationship between the two traits (Table 4). Finally, low resistance costs $(\mathrm{rc}=0)$ produced a trade-off (negative relationship) between resistance and competitive ability (Table 4, Fig. 5).

Bivariate nonlinear selection gradient analyses $(\gamma)$ measuring selection on combinations of traits, revealed that these trade-offs resulted from selection on particular combinations of resistance and competitive response values. At low resistance costs $(\mathrm{rc}=0)$, selection favored genotypes with high CR and high resistance, creating a trade-off between resistance and competitive response (Table 5, Fig. 5). Fig. 5 shows that at high resistance costs $(\mathrm{rc}=0.20)$, selection favored genotypes with low resistance and high CR (Table 5). This pattern of selection resulted in a positive relationship between the two traits (Table 5).

\section{Discussion}

Our model shows that competition has drastically different effects on the evolution of competitive response and competitive effect. Competitive response, the ability to grow and reproduce in the presence of competitors, evolved quickly regardless of the mode of competition, whereas competitive effect, the ability to suppress neighbors, did not. Competitive suppression between members of the same genotype prevented selection for high $\mathrm{CE}$, whereas the benefits of having a high CE for suppressing non-kin neighbors prevented selection against CE. The evolution of resistance was independent of the evolution of competitive ability and was only favored at low resistance costs. Resistance costs played a crucial role in determining both the direction and strength of trade-offs between competitive ability and resistance.

\section{Evolution of competitive ability}

Selection gradient analysis indicated that intraspecific competition was the major selective force in our simulations. The number of genotypes was reduced from an initial 500 to an average of 108 genotypes in $40 \mathrm{yr}$, an average mortality of 10 genets per year $(2 \%$ mortality rate). Surprisingly, a two-year study of Solidago altissima growth and mortality (Cain 1990a) found little evidence that ramet mortality or size hierarchies were structured by intraspecific competition. There are several plausible explanations for the discrepancy between empirical and theoretical results. First, our model tracked 500 genotypes, of which only $2 \%$ died each year. A two-year study of a limited num-

TABLE 4. Effects of resistance costs (rc) on number of genotypes alive after selection, competitive effect, competitive response, resistance, and trade-offs between the later three traits after 40 years of selection pressure from herbivores.

\begin{tabular}{|c|c|c|c|c|c|c|c|}
\hline \multirow[b]{2}{*}{ Parameter } & \multicolumn{2}{|c|}{$\mathrm{rc}=0.0$} & \multicolumn{2}{|c|}{$\mathrm{rc}=0.10$} & \multicolumn{2}{|c|}{$\mathrm{rc}=0.20$} & \multirow[b]{2}{*}{$P$} \\
\hline & Mean & $1 \mathrm{SE}$ & Mean & $1 \mathrm{SE}$ & Mean & $1 \mathrm{SE}$ & \\
\hline Number of genotypes & 107.75 & 1.82 & 106.10 & 1.82 & 96.2 & 1.182 & $<0.0001$ \\
\hline Competitive effect & 1.03 & 0.003 & 1.04 & 0.003 & 1.03 & 1.003 & 0.19 \\
\hline Competitive response & 1.13 & 0.001 & 1.14 & 0.001 & 1.14 & 0.001 & 0.18 \\
\hline Resistance & 0.47 & 0.007 & 0.40 & 0.007 & 0.33 & 0.007 & $<0.0001$ \\
\hline \multicolumn{8}{|l|}{ Trade-offs } \\
\hline Resistance vs. competitive effect & 0.005 & 0.04 & 0.036 & 0.04 & -0.058 & 0.04 & 0.31 \\
\hline Resistance vs. competitive response & -0.10 & 0.04 & 0.014 & 0.04 & 0.24 & 0.04 & $<0.0001$ \\
\hline Competitive effect vs. competitive response & -0.038 & 0.055 & 0.079 & 0.055 & -0.027 & 0.055 & 0.26 \\
\hline
\end{tabular}

Notes: Data are from the end of 40-yr runs $(n=10)$; df $=3$, 496. Results are averaged for symmetric and asymmetric competition. 
TABLE 5. Effects of resistance costs (rc) on (a) standardized selection coefficients $(\beta)$ for resistance, competitive effect, and competitive response; (b) Selection gradient bivariate selection $(\gamma)$ for covariances between the three traits.

\begin{tabular}{|c|c|c|c|c|c|c|c|}
\hline \multirow[b]{2}{*}{ Parameter } & \multicolumn{2}{|c|}{$\mathrm{rc}=0.0$} & \multicolumn{2}{|c|}{$\mathrm{rc}=0.10$} & \multicolumn{2}{|c|}{$\mathrm{rc}=0.20$} & \multirow[b]{2}{*}{$P$} \\
\hline & Mean & $1 \mathrm{SE}$ & Mean & $1 \mathrm{SE}$ & Mean & $1 \mathrm{SE}$ & \\
\hline \multicolumn{8}{|l|}{ a) Standardized selection coefficients $(\beta)$} \\
\hline Resistance $(\beta)$ & 0.15 & 0.01 & 0.001 & 0.01 & -0.4 & 0.01 & $<0.0001$ \\
\hline Competitive effect $(\beta)$ & -0.026 & 0.008 & -0.007 & 0.008 & -0.019 & 0.008 & 0.33 \\
\hline Competitive response $(\beta)$ & 0.49 & 0.007 & 0.50 & 0.007 & 0.47 & 0.007 & 0.002 \\
\hline \multicolumn{8}{|c|}{ b) Selection gradient bivariate selection $(\gamma)$} \\
\hline $\begin{array}{l}\text { Resistance and competitive } \\
\text { effect }(\gamma)\end{array}$ & -0.036 & 0.01 & 0.0008 & 0.01 & 0.06 & 0.01 & 0.11 \\
\hline $\begin{array}{l}\text { Resistance and competitive } \\
\text { response }(\gamma)\end{array}$ & 0.19 & 0.015 & 0.017 & 0.015 & -0.19 & 0.015 & $<0.0001$ \\
\hline $\begin{array}{l}\text { Competitive effect and competitive } \\
\text { response }(\gamma)\end{array}$ & -0.038 & 0.018 & 0.007 & 0.018 & -0.036 & 0.018 & 0.15 \\
\hline
\end{tabular}

Notes: Data are standardized to mean $=0$ and standard deviation $=1$ for analyses; results are averaged for symmetric and asymmetric competition. Boldface numerals indicate that all of the coefficients in the simulations were significant at $P$ $\leq 0.05$. For $\beta$ analyses, df $=3$, 496; for $\gamma$ analyses, $\mathrm{df}=9,490$.

ber of genotypes easily could have missed any mortality. A second possibility is that our model overestimated mortality. In his two-year study, Cain (1990a) found that $83 \%$ of dead ramets were connected to living ramets. Our model did not consider intraclonal connections and resource sharing among ramets, which may be crucial determinants of mortality in clonal plant

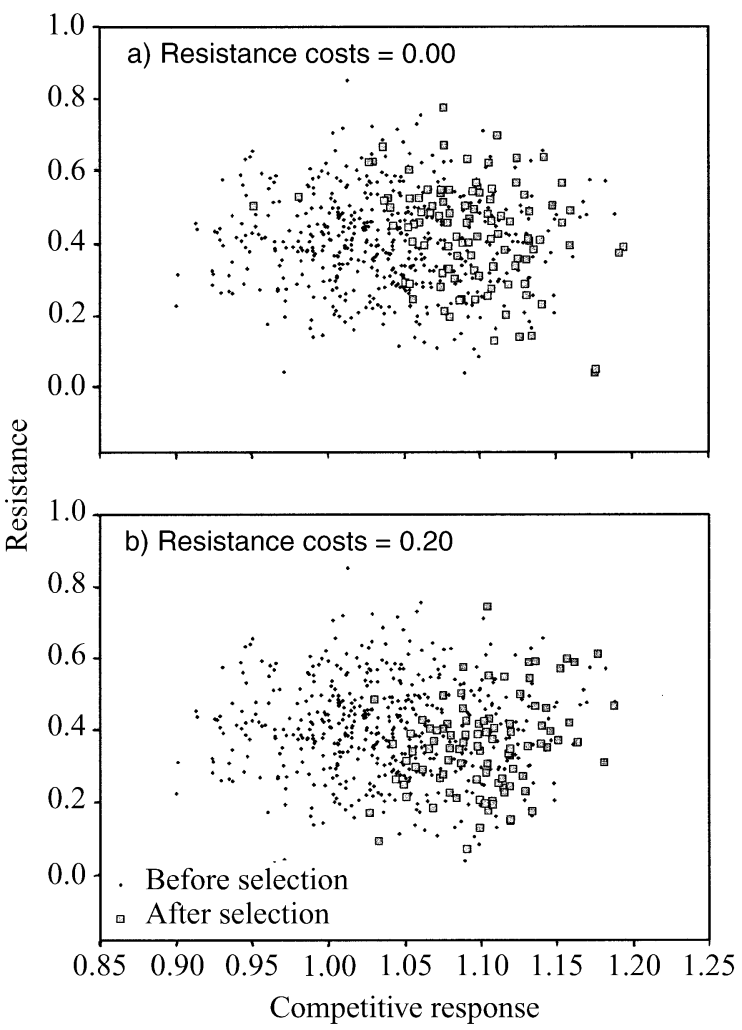

FIG. 5. Scatter graph of resistance and competitive response in initial population and in genotypes remaining at the end of $40 \mathrm{yr}$ of selection, under two levels of resistance costs, $\mathrm{rc}=0.0,0.20$. populations, particularly under environmental stress (Hartnett and Bazzaz 1983, Tiffney and Niklas 1985).

The strength of selection from intraspecific competitors on the evolution of competitive ability was markedly different for the two components of competitive ability. Competition favored genotypes with high competitive response; that is, it favored the evolution of traits that allow a plant to grow or persist in competition (i.e., competition tolerance). In a previous empirical study, Goldberg (1988) found little differentiation between $S$. altissima clones in response to intra- and interspecific competition. Goldberg reasoned that these clones represented survivors after selection for good competitors from the initial population. In our model, we observed rapid selection for genotypes with high $\mathrm{CR}$ and reduced variation in this trait among genotypes after a few years of selection. Such rapid selection lends support to a large body of literature suggesting that empirical detection of the selective effects of competition is difficult, particularly in studies of short duration (Connell 1980, 1983, Goldberg and Barton 1983).

Empirical studies may also benefit from considering specific traits associated with competitive ability. Our model demonstrates that the risk of self-suppression may prevent the evolution of traits that give perennial plants the ability to suppress their neighbors (e.g., stem elongation in response to shading). There is little empirical evidence for genetic variation in competitive effect in perennial plants, a prerequisite for evolution. Several studies have demonstrated that per unit size competitive effects are equivalent among species (Goldberg 1987, Goldberg and Fleetwood 1987, Miller and Werner 1987). These studies suggest that competitive effect is not a genetic trait per se, but rather a consequence of plant growth patterns.

The disparity in the evolution of the two components of competitive ability also suggests that being tolerant of competition is a more successful strategy than hav- 
ing the ability to suppress competitors. In successional environments, turnover in community composition is high and neighborhood composition is highly variable. Competitive effect will vary between particular pairs of species, but being tolerant of competition (CR) may be a more effective strategy for persistence, regardless of the identity of competitors (Parrish and Bazzaz 1982, Goldberg 1987). In other words, evolution of competitive response to one or several competitors over evolutionary time may preclude competitive exclusion in ecological time (Aarsen 1992; M. Uriarte and H. K. Reeve, unpublished manuscript).

An alternative explanation for the divergence in the evolutionary trajectory of CE and CR is that there are no inherent differences between the two components of competitive ability (CR and $\mathrm{CE}$ ), but rather built-in differences in the strength of these factors in our model and, hence, on their potential effects on fitness. We compare the strength of these factors in the Appendix and conclude that the difference in the evolution of the two components of competitive ability is inherent to their nature rather than an artifact of the model.

\section{Simultaneous evolution of competitive ability and resistance}

Resistance had a secondary role in determining the genetic structure of the population. The rate of genet mortality was unaffected by herbivore pressure and remained steady for the first $30 \mathrm{yr}$ of the simulations, decreasing only in the last $10 \mathrm{yr}$. Resistance costs became more important in the later stages of succession. Selection for resistance during the first $30 \mathrm{yr}$ of the simulations increased the mean resistance of the population. The reduction in herbivore pressure in the last $10 \mathrm{yr}$ decreased the benefits derived from previously evolved resistance.

Our selection gradient analyses showed that resistance was only beneficial at very low resistance costs. Herbivores remove, on average, $10-20 \%$ of leaf tissue and their effects are patchy in time and space (Bazzaz et al. 1987). The strength of selection from herbivores may not be enough to warrant high costs of resistance. In their review, Bergelson and Purrington (1996) found costs of herbivore resistance for only $26 \%$ of the studies included in their survey.

In our simulations, and in many natural communities, competition is a steadier selective force than insect damage (Hartnett and Bazzaz 1985b, Goldberg 1988, Root and Cappuccino 1992). Selection from competition with conspecifics may favor genotypes with vigorous growth. In natural populations, some goldenrod herbivores preferentially attack more vigorous plant genotypes; thus herbivore damage may serve to reduce the fitness differences between superior and inferior competitors (Craig et al. 1999; M. Uriarte and R. B. Root, unpublished manuscript).

The physiological traits required for fast growth may also make a good competitor more tolerant of herbivore damage. Traits that evolve as a response to the selective pressures of competition may be co-opted to tolerate herbivore damage (Aarsen and Irwin 1991, Aarsen 1995). However, other tolerance mechanisms, such as production of new meristems or changes in resource allocation after damage, suggest that the evolution of vigorous growth rates in response to competition cannot solely account for the evolution of tolerance (Strauss and Agrawal 1999, Hochwender et al. 2000, Stowe et al. 2000)

\section{Trade-offs between competitive ability and resistance}

Trade-offs between resistance and competitive ability are more likely to exist when costs of resistance are low. At high costs of resistance, we found a positive relationship between competitive ability and resistance. Unpredictable herbivore pressure and high costs of resistance may favor the evolution of induced resistance (Karban and Baldwin 1997). Plants with induced resistance only pay the cost of resistance when attacked by herbivores. When herbivore damage is sporadic and the level of induction is proportional to damage, the trade-off between competitive ability and resistance might be maintained (Baldwin and Schmelz 1994, Baldwin and Hamilton 2000).

High growth rates (i.e., competitive response) may also give good competitors the ability to recover quickly from tissue loss to herbivores. In such case, tradeoffs between competitive response and resistance could translate into trade-offs between herbivore tolerance and resistance. These trade-offs have been reported for a number of species and appear to be alternative strategies to cope with herbivore damage (Feinblum and Rausher 1995, Strauss and Agrawal 1999, Stowe et al. 2000). Many herbivores are specialists and are probably attracted to the compounds responsible for resistance. Thus, specialist pressure may further favor the evolution of tolerance. In addition, the ability of perennial plants to recover from damage by relying on their stored resources may slow down the evolution of resistance in favor of increased tolerance, particularly if resistance costs are high (Crawley 1983, Marquis 1992).

\section{Revisiting the assumptions of the model}

The validity of any model rests on its assumptions. Here we revisit our assumptions and explore how they may have affected the conclusions that we have drawn from our simulations.

At a basic level, some readers might not agree with our formulation of competitive response and effect. Competitive response and effect encompass a variety of plant mechanisms and our interpretation may not include all of them (Goldberg 1990). For instance, high competitive response can be a result of increased resource uptake, decreased resource loss, increased efficiency of conversion, or the ability to store resources during periods of high resource abundance (Goldberg 
1990). We have chosen a phenomenological interpretation of competitive response and competitive effect by implementing competitive effect as the weight of a neighbor on a given target plant and competitive response as the ability to grow regardless of the number of neighbors. An alternative interpretation may have been to model competitive response as differential mortality in response to competition or differential ability to produce rhizomes in the presence of competitors. We conducted additional simulations using these interpretations and our results were similar. Thus, our simulations are representative of several possible mechanisms that make plants superior competitors in natural populations.

Likewise, our interpretation of competitive effect is quite literal and, perhaps, objectionable. Larger plants tend to have high RGR and greater per unit size competitive effects on their neighbors (Goldberg 1990). In our model, we associate a high competitive response with greater RGR. We interpret competitive effect as allocation of resources to roots or efficiency in the architecture of resource-acquiring organs, but other interpretations are possible and would lead to different results.

We did not model intraclonal connections, but resource sharing between different parts of a clone occurs in natural goldenrod populations (Hartnett and Bazzaz 1983, 1985b). It is possible that resource sharing among ramets would have reduced the intensity of the self-suppression effect in the evolution of competitive effect. However, clonal integration is not always beneficial to individual ramets in the genet. In tall goldenrod, resource sharing does occur between mother rhizome and daughter ramets, but not between sister ramets. Instead, sister ramets compete for resources from the common mother rhizome (Abrahamson et al. 1991). Competition between sister ramets may occur in nature because taller ramets create an osmotic gradient that draws nutrients away from smaller ramets (Abrahamson et al. 1991). In our model, we allowed for resource sharing between mother rhizome and daughter ramets by including a carryover effect derived from mother size, but we allowed competition between sister ramets if they were in the same neighborhood. The self-suppression effect that we observed between sister ramets in the evolution of competitive effect may exist in nature even when ramet connections are present (Schmid and Bazzaz 1987, Abrahamson et al. 1991).

We assumed that plants do not "forage" and that soil resources and herbivore damage are spatially uniform across the population. However, both soil resources and herbivore damage are often heterogeneous in the environment. In natural populations, plants can increase the length of their rhizomes under unfavorable conditions (e.g., high competition, low nutrients) and "disperse" into a more favorable patch (e.g., avoiding competitors and low resource availability) by producing longer rhizomes (Abrahamson et al. 1991, Stoll et al. 1998). Such "foraging" has an adaptive value (van Kleunen and Fischer 2001). Moreover, resources are constant in our model, whereas soil resources are heterogeneous in time and space for natural populations (Uriarte 2000). Reductions in resource availability might alter the intensity and nature of competition.

We also failed to consider interspecific competition. In natural populations, insect outbreaks reduce goldenrod densities and enable invasion by other plant species, changing the nature of competition from intra- to interspecific (Root 1996, Carson and Root 2000). It is rare that goldenrod dominates old fields beyond 30$40 \mathrm{yr}$ after establishment. In our model, herbivore damage brings about a temporary decrease in intraspecific competition, but goldenrod densities quickly return to pre-attack levels. In nature, these reductions in density may bring about an opportunity for the establishment of tree seedlings by opening up small gaps that allow these seedlings to become tall enough to out-compete neighboring goldenrods (Gill and Marks 1991, Carson and Root 2000). In the absence of these gaps, establishment of tree seedlings in a goldenrod-dominated old field is rare (Gill and Marks 1991). The evolution of competitive ability may slow down the establishment of woody species by favoring genotypes with vigorous growth and, hence, the ability to produce a large number of rhizomes and fill out existing gaps. Other factors such as the production of a favorable seed crop and the level of seed herbivory from small mammals are also crucial in seedling establishment (Rankin and Pickett 1989). The introduction of new plant competitors may reduce herbivore pressure by changing microclimatic conditions, or may alter the direction of selection for particular traits that affect competitive ability. However, once trees overtop the herbaceous canopy, competitive exclusion of goldenrod occurs quickly, eliminating opportunities for selection.

\section{Concluding remarks}

We took advantage of the extensive goldenrod literature to develop a realistic model of the evolution of perennial plants to two stresses: competition and herbivore pressure. This approach allowed us to ask questions about the evolution of competitive ability, a difficult task for empiricists. The primacy of competitive ability as a selective factor suggests that further work in this area is warranted. A better understanding of the traits that determine competitive ability in perennial plants is required. For instance, kin selection may act to prevent the evolution of competitive traits (i.e., stem elongation in response to shading) that diminish fitness of neighbors.

Goldenrod has one of the richest and most studied herbivore faunas of temperate perennial plants. The fact that pressure from these herbivores is only strong enough to bear low costs of resistance argues against the generalized existence of costs. The strong selective effects of competitors coupled with the weak selection 
from herbivores suggest that plant traits directly associated with growth that confer tolerance to both competitors and consumers may be the targets of selection.

\section{ACKNOWLEDGMENTS}

We thank M. L. Cain, R. F. Denno, M. A. Geber, P. L. Marks, H. K. Reeve, and A. E. Weis for useful comments on the manuscript. We acknowledge support from an Anonymous Donor Fellowship and an NSF HAEC (Human Accelerated Environmental Change) Research Training Grant to M. Uriarte. This study is a contribution to the program of the Institute of Ecosystem Studies.

\section{Literature Cited}

Aarsen, L. W. 1992. Causes and consequences of variation in competitive ability in plant communities. Journal of Vegetation Science 3(2): 165-174.

Aarsen, L. W. 1995. Hypothesis for the evolution of apical dominance in plants: implications for the interpretation for overcompensation. Oikos 74:149-156.

Aarsen, L. W., and D. Irwin. 1991. What selection: herbivory or competition? Oikos 60:261-262.

Abrahamson, W. G., S. S. Anderson, and K. D. McCrea. 1988. Effects of manipulation of plant carbon nutrient balance on tall goldenrod resistance to a gallmaking herbivore. Oecologia 77:302-306.

Abrahamson, W. G., S. S. Anderson, and K. D. McCrea. 1991. Clonal integration nutrient sharing between sister ramets of Solidago altissima Compositae. American Journal of Botany 78:1508-1514.

Agren, J., and D. W. Schmeske. 1994. Evolution of trichome number in a naturalized population of Brassica rapa. American Naturalist 143:1-13.

Anderson, S. S., K. D. McCrea, and W. G. Abrahamson. 1989. Host genotype choice by the ball gallmaker (Eurosta solidaginis (Diptera: Tephritidate). Ecology 70:1048-1054.

Annicchiaricco, P., and E. Piano. 1997. Effect of selection under cultivation on morphological traits and yield of Ladino white clover land races. Genetics Resources and Crop Evolution 44:405-410.

Baldwin, I. T. 1998. Jasmonate induced responses are costly but benefit plants under attack in native populations. Proceedings of the National Academy of Sciences (USA) 95: 8113-8118.

Baldwin, I. T., and W. Hamilton III. 2000. Jasmonate-induced responses of Nicotiana sylvestris results in fitness costs due to impaired competitive ability for nitrogen. Journal of Chemical Ecology 26:915-952.

Baldwin, I. T., and E. A. Schmelz. 1994. Constraints on an induced defense: the role of leaf area. Oecologia 97:424430.

Bazzaz, F. A., N. R. Chiarello, P. D. Coley, and L. F. Pitelka. 1987. Allocating resources to reproduction and defense BioScience 37:58-67.

Bergelson, J., and C. B. Purrington. 1996. Surveying patterns in the cost of resistance in plants. American Naturalist 148: 536-558.

Brodie, E. D., A. J. Moore, and F. J. Janzen. 1995. Visualizing and quantifying natural selection. Trends in Ecology and Evolution 10:313-318.

Cain, M. L. 1990a. Patterns in Solidago altissima ramet growth and mortality: the role of belowground ramet connections. Oecologia 82:201-209.

Cain, M. L. 1990b. Models of clonal growth in Solidago altissima. Journal of Ecology 78:27-46.

Cain, M. L., W. P. Carson, and R. B. Root. 1991. Long-term suppression of insect herbivores increases the production and growth of Solidago altissima rhizomes. Oecologia 88: 251-257.

Carson, W. P., and R. B. Root. 2000. Herbivory and plant species coexistence: community regulation by an outbreaking phytophagous insect. Ecological Monographs 70:7399.

Coley, P. D., J. P. Bryant, and F. S. Chapin. 1985. Resource availability and plant anti-herbivore defense. Science 230: 895-899.

Connell, J. H. 1980. Diversity and the coevolution of competitors, or the ghost of competition past. Oikos 35:131138.

Connell, J. H. 1983. On the prevalence and relative importance of interspecific competition: evidence from field experiments. American Naturalist 122:661-696.

Craig, T. P., W. G. Abrahmason, J. K. Itami, and J. D. Horner. 1999. Oviposition preference and offspring performance on genotypes of Solidago altissima. Oikos 86:119-128.

Crawley, M. J. 1983. Herbivory: the dynamics of animalplant interactions. Blackwell Scientific, Oxford, UK.

Cronquist, A. 1980. Vascular flora of the southeastern U.S. Volume 1. Asteraceae. University of North Carolina Press, Chapel Hill, North Carolina, USA.

Elle, E., N. vanDam, and D. J. Hare. 1999. Cost of glandular trichomes, a resistance character in Datura wrightii regel (Solanaceae). Evolution 53:22-35.

Feinblum, W. L., and M. D. Rausher. 1995. Tradeoff between resistance and tolerance to herbivore damage in a morning glory. Nature 377:517-520.

Gill, D. S., and P. L. Marks. 1991. Tree and shrub seedling colonization of old fields in central New York. Ecological Monographs 61:183-205.

Goldberg, D. E. 1987. Neighborhood competition in an oldfield plant community. Ecology 68:1211-1223.

Goldberg, D. E. 1988. Response of Solidago canadensis clones to competition. Oecologia 77:357-364.

Goldberg, D. E. 1990. Components of resource competition in plant communities. Pages 27-49 in J. B. Grace and D. Tilman, editors. Perspectives on plant competition. Academic Press, San Diego, California, USA.

Goldberg, D. E., and A. M. Barton. 1992. Patterns and consequences of interspecific competition in natural communities: a review of field experiments with plants. American Naturalist 139:771-801.

Goldberg, D. E., and L. Fleetwood. 1987. Competitive effect and response in four annual plants. Journal of Ecology 75: $1131-1144$.

Grace, J. B., and D. G. Tilman. 1990. Perspectives on plant competition. Academic Press, San Diego, California, USA.

Hartnett, D. C. 1990. Size-dependent allocation to sexual and vegetative reproduction in four clonal composites. Oecologia 84:254-259.

Hartnett, D. C., and F. A. Bazzaz. 1983. Physiological integration among intraclonal ramets in Solidago canadensis. Ecology 64:779-788.

Hartnett, D. C., and F. A. Bazzaz. 1985a. The genet and ramet population dynamics of Solidago canadensis in an abandoned field. Journal of Ecology 73:407-413.

Hartnett, D. C., and F. A. Bazzaz. 1985b. The regulation of leaf ramet and genet densities in experimental populations of the rhizomatous perennial Solidago canadensis. Journal of Ecology 73:429-444.

Herms, D. A., and W. J. Mattson. 1992. The dilemma of plants: to grow or to defend. Quarterly Review of Biology 67:283-335.

Hochwender, C., R. Marquis, and K. Stowe. 2000. The potential for and constraints on the evolution of compensatory ability in Asclepias syrica. Oecologia 122:361-370.

Karban, R., and I. T. Baldwin. 1997. Induced responses to herbivory. University of Chicago Press, Chicago, Illinois, USA.

Lande, R., and S. J. Arnold. 1983. The measurement of selection on correlated characters. Evolution 37:1210-1226. 
Louda, S. M., K. H. Keeler, and R. D. Holt. 1990. Herbivore influences on plant performance and competitive interactions. Pages 413-444 in J. B. Grace and D. Tilman, editors. Perspectives on plant competition. Academic Press, San Diego, California, USA.

Maddox, G. D., and R. B. Root. 1987. Resistance to 16 diverse species of herbivorous insects within a population of goldenrod, Solidago altissima: genetic variation and heritability. Oecologia 72:8-14.

Maddox, G. D., and R. B. Root. 1990. Structure of the encounter between goldenrod (Solidago altissima) and its diverse insect fauna. Ecology 71:2115-2124.

Marquis, R. J. 1992. Selective impact of herbivores. Pages 301-325 in R. S. Fritz and E. L. Simms, editors. Plant resistance to herbivores and pathogens. University of Chicago Press, Chicago, Illinois, USA.

Mauricio, R. 1998. Cost of resistance to natural enemies in field populations of the annual plant Arabidopsis thaliana. American Naturalist 151:20-28.

McCrea, K. D., and W. G. Abrahamson. 1987. Variation in herbivore infestation: historical vs. genetic factors. Ecology 68:822-827.

Miller, T. E. 1995. Evolution of Brassica rapa L. (Cruciferae) population in intra- and interspecific competition. Evolution 49:1125-1133.

Miller, T. E., and P. A. Werner. 1987. Competitive effects and responses between plants in a first-year old-field community. Ecology 68:1201-1210.

Mitchell-Olds, T., D. Siemens, and D. Pedersen. 1996. Physiology and costs of resistance to herbivory and disease in Brassica. Entomologia Experimentalis and Applicata 80: 231-237.

Morris, W. F., P. L. Marks, C. L. Mohler, N. R. Rappaport, F. R. Wesley, and M. A. Moran. 1986. Seed dispersal and seedling emergence in an old-field community in Central New York. Oecologia 70:92-99.

Niemann, G. J., J. B. M. Pureveen, E. Gert, P. Hendrik, and B. Jaap. 1995. Differential chemical allocation and plant adaptation: a Py-MS study of 24 species differing in relative growth rate. Plant and Soil 175:275-289.

Nuñez, F, and R. Dirzo. 1994. Evolutionary ecology of Datura stramonium, L. in central Mexico: Natural selection for resistance to herbivorous insects. Evolution 48:423436.

Parrish, J. A. D., and F. A. Bazzaz. 1982. Competitive interactions in plant communities of different successional ages. Ecology 63:314-320.

Rankin, W. T., and S. T. A. Pickett. 1989. Time of establishment of red maple (Acer rubrum) in early old field succession. Bulletin of the Torrey Botanical Club 116:182186.

Rausher, M. D., K. Iwao, E. L. Simms, N. Ohsaki, and D. Hall. 1993. Induced resistance in Ipomoea purpurea. Ecology 74:20-29.

Rausher, M. D., and E. L. Simms. 1989. The evolution of resistance to herbivory in Ipomea purpurea I. Attempts to detect selection. Evolution 43:563-572.

Root, R. B. 1996. Herbivore pressure on goldenrods: its variation and cumulative effects. Ecology 77:1074-1087.

Root, R. B., and N. Cappuccino. 1992. Patterns in population change and the organization of the insect community associated with goldenrod. Ecological Monographs 62:393420.

SAS Institute. 1997. SAS/STAT software: changes and enhancement through release 6.12. SAS Institute, Cary, North Carolina, USA.

Schmid, B., and F. A. Bazzaz. 1987. Clonal integration and population structure in perennials: effects of severing rhizome connections. Ecology 68:2016-2022.

Schmid, B., F. A. Bazzaz, and J. Weiner. 1995. Size-dependency of sexual reproduction and of clonal growth in two perennial plants. Canadian Journal of Botany 73:18311837.

Schwinning, S., and J. Weiner. 1998. Mechanisms determining the degree of size asymmetry in competition among plants. Oecologia 113:447-455.

Simms, E. L. 1992. Cost of plant resistance to herbivores. Pages 392-425 in R. Fritz and E. L. Simms, editors. Plant resistance: ecology and evolution. University of Chicago Press, Chicago, Illinois, USA.

Stoll, P., P. Egli, and B. Schmid. 1998. Plant foraging and rhizome growth patterns of Solidago altissima in response to mowing and fertilizer application. Journal of Ecology 86:341-354.

Stowe, K. A., R. J. Marquis, C. G. Hochwender, and E. L. Simms. 2000. The evolutionary ecology of tolerance to consumer damage. Annual Review of Ecology and Systematics 31:565-595.

Strauss, S. Y., and A. A. Agrawal. 1999. The ecology and evolution of plant tolerance to herbivory. Trends in Ecology and Evolution 14:179-185.

Tiffney, B. H., and K. J. Niklas. 1985. Clonal growth in land plants: a paleobiological perspective. Pages 35-66 in J. B. C. Jackson, L. W. Buss, and R. E. Cook, editors. Population biology and evolution of clonal organisms. Yale University Press, New Haven, Connecticut, USA.

Uriarte, M. 2000. Interactions between goldenrod (Solidago altissima L.) and its insect herbivore (Trirhabda virgata) over the course of succession. Oecologia 122:521-528.

Van Kleunen, M., and M. Fischer. 2001. Adaptive evolution of plastic foraging responses in a clonal plant. Ecology 82: $3309-3319$.

Weis, A. E., and M. E. Hochberg. 2000. The diverse effects of intraspecific competition on the selective advantage to resistance: a model and its predictions. American Naturalist 156:276-292.

Werner, P. A., I. K. Bradbury, and R. S. Gross. 1980. The biology of Canadian weeds, 45. Solidago canadensis, L. Canadian Journal of Plant Science 60:1393-1409.

\section{APPENDIX}

A Comparison of the Magnitude of the Effects of Competitive Response and Competitive Effects ON THE Fitness of A GoldenRod Genotype

There are some conceptual difficulties in comparing the magnitude of $\mathrm{CR}$ and $\mathrm{CE}$. Competitive response is a trait that affects a genotype's growth directly, whereas CE affects growth indirectly, by altering the intensity of intraspecific competition from neighbors. These caveats aside, here we attempt to compare the strength of these two factors by contrasting the CR of one ramet of genotype $\mathrm{X}$ with the CE of a second ramet belonging to the same genotype $\mathrm{X}$.

Competitive response and competitive effect can affect the fitness of a given genotype by altering actual RGR, height, and hence the probability of survival and the number of rhizomes produced.

Competitive response (CR) is factored directly into Eq. 2:

$$
A=H \times P \times \mathrm{CI} \times \mathrm{CR} \times \text { Cost. }
$$

Competitive effect is factored into the calculation of crowding index in Eq. 6, modifying the effective density of neighbors by a factor of CE: 


$$
\mathrm{CI}=\exp \left(-\alpha\left(\sum_{j} \text { effective density }_{j}\right)^{\beta}\right) .
$$

It is difficult to compare the magnitude of $\mathrm{CR}$ and $\mathrm{CE}$ on the growth of an individual plant because CR affects growth directly, whereas CE alters the growth of neighbors, which in turn feed back to affect the growth of the target plant.

We can estimate the difference in the magnitude of these effects by considering the case in which two ramets of the same genotype are growing side by side. For the sake of simplicity, we will assume that these two ramets have identical CR and CE. As indicated in the model description section, CR and CE are drawn from the same underlying distribution. We can choose one of the ramets and compare the effects of its CR on multiplier A with the effects of CE from the second ramet on the same multiplier.

(a) Effects of $\mathrm{CR}$ on multiplier $\mathrm{A}_{1}$ of ramet 1 equal the value of $C R$.

(b) Effects of $\mathrm{CE}$ of ramet 2 on ramet 1 multiplier $\mathrm{A}_{1}$ :

$$
\mathrm{CE}=\exp \left(-\alpha(\mathrm{CE})^{\beta}\right) .
$$

$\mathrm{CE}$ and $\mathrm{CR}$ are both drawn from the same normal distribution centered around 1. If we assume that $\mathrm{CE}=1$ and $\alpha=-0.15$ and $\beta=1.5$ (the parameters used in all of our runs; Table $1)$ :

$$
\begin{aligned}
& \mathbf{C R}=1 \\
& \mathbf{C E}=\exp \left(-0.15^{1.5}\right)=0.86 .
\end{aligned}
$$

The effects of the multiplier are propagated through the RGR term in Eq. 1:

$$
\mathrm{RGR}_{\mathrm{pot}}=A \exp (-0.75 \text { month }) \text {. }
$$

Thus, the effects of CR (or CE) on actual RGR are:

$$
\mathrm{RGR}_{\text {act }}=\mathrm{CR}(\mathrm{CE}) \exp (-0.75 \text { month }) \text {. }
$$

The effects of $\mathrm{RGR}_{\text {act }}$ (Eq. 3) on growth are:
TABLE A1. Height differences calculated for CR and CE.

\begin{tabular}{cccc}
\hline \hline $\mathrm{CR}=\mathrm{CE}$ & Diff. (cm) & Diff. (\%) & $\begin{array}{c}\text { Height diff. } \\
\text { in favor of: }\end{array}$ \\
\hline 0.8 & 6 & 3.0 & $\mathrm{CR}$ \\
1 & 8 & 3.7 & $\mathrm{CE}$ \\
1.2 & 23 & 10.22 & $\mathrm{CE}$ \\
\hline
\end{tabular}

$$
\text { Height }_{t+1}=\exp \left(\left(0.3 \mathrm{RGR}_{\text {act }}\right)+\ln \left(\text { height }_{t}\right)\right) \text {. }
$$

We assume a starting height of $10 \mathrm{~cm}$. Height at $t+1$ is really the increment in size added to the previous period $(t)$ growth.

$$
\text { Height }_{t+1}=\exp \left(\left(0.3 \mathrm{RGR}_{\text {act }}\right)+\ln \left(\text { height }_{t}\right)\right) .
$$

The difference in height propagated through differences in the multiplier at various values of $\mathrm{CE}=\mathrm{CR}$ are given in Table A1. We use maximum, minimum, and average values that $\mathrm{CE}$ and $\mathrm{CR}$ take in our simulations, and calculate the resulting difference in height for each case. This difference in height, in the most drastic case $(10 \%)$, would translate into the following differences in the number of rhizomes $(n)$ :

$$
n=a+b \text { (height) } \quad n=0.037+0.039 \text { (height). }
$$

In the case in which a plant attains its greatest possible height $(150 \mathrm{~cm})$, the difference in height will be $15 \mathrm{~cm}$ :

$$
\begin{aligned}
& \text { Diff.fitness }=0.039 \text { (Diff.height) } \\
& \text { Diff.fitness }=0.039 \times 15 \mathrm{~cm}=0.585 .
\end{aligned}
$$

This is a small difference, given that, on average, a plant of $150 \mathrm{~cm}$ in height produces 5.9 rhizomes $(10 \%$ decrease in fitness). In other cases with values of CR and CE closer to the mean of the population, the difference will be even smaller and thus unlikely to cause the difference in the evolution of $\mathrm{CR}$ and $\mathrm{CE}$ that we observed in our simulations. 